\title{
Bevacizumab, pemetrexed and carboplatin in first-line treatment of non-small cell lung cancer patients: Focus on patients with brain metastases
}

\author{
DIMITRA STEFANOU, SOFIA STAMATOPOULOU, ANTIGONI SAKELLAROPOULOU, GAVRIIL AKAKIOS, \\ MARINA GKIAOURAKI, DESPINA GKEKA, MARIA PREVEZANOU and ALEXANDROS ARDAVANIS
}

First Department of Medical Oncology, St. Savas Anticancer Hospital, Athens 115 22, Greece

Received October 29, 2015; Accepted April 5, 2016

DOI: $10.3892 / 01.2016 .5268$

\begin{abstract}
Data concerning bevacizumab plus pemetrexed plus carboplatin as first-line treatment for patients with non-squamous non-small cell lung cancer (NSCLC) with or without brain metastases (BM) are lacking. The present study analyzed the efficacy and safety of this combination as induction therapy, followed by maintenance therapy with bevacizumab plus pemetrexed in non-squamous NSCLC patients with or without BM. Treatment-naïve patients with advanced non-squamous NSCLC and an Eastern Cooperative Oncology Group performance status score of $0-2$ were eligible. Treatment consisted of carboplatin (area under the curve of 5), pemetrexed $\left(500 \mathrm{mg} / \mathrm{m}^{2}\right)$ and bevacizumab $(15 \mathrm{mg} / \mathrm{kg})$ every 3 weeks for 6 cycles. Responders and patients with stable disease received maintenance therapy with bevacizumab plus pemetrexed until disease progression, which was evaluated every 3 cycles, or unacceptable toxicity. Kaplan-Meier median progression-free survival (PFS) and overall survival (OS) times were the primary endpoints, and safety was the secondary endpoint. In total, 39 patients, aged 44-78 years (median, 60 years), were treated; $11(28.2 \%)$ of whom presented with BM. The majority of patients (56.4\%) completed 6 cycles of induction therapy, and 26 patients continued on to maintenance therapy. The median PFS time was 8.2 months [95\% confidence interval (CI), 7.05-9.35] and the median OS time was 14.0 months (95\% CI, 8.46-19.54). Median PFS and OS times did not differ significantly between patients with or without BM (log rank (Mantel-Cox): PFS, $\mathrm{P}=0.748$ and $\mathrm{OS}, \mathrm{P}=0.447$ ). The majority of patients (76.9\%) did not experience adverse events during treatment. Overall, bevacizumab plus pemetrexed plus carboplatin as induction therapy, followed by bevacizumab plus
\end{abstract}

Correspondence to: Dr Alexandros Ardavanis, First Department of Medical Oncology, St. Savas Anticancer Hospital, 171 Alexandras Avenue, Athens 115 22, Greece

E-mail: ardavanis@yahoo.com

Key words: carcinoma, non-small cell lung cancer, chemotherapy, bevacizumab, pemetrexed, carboplatin, brain metastases pemetrexed as maintenance therapy was effective and well tolerated in advanced NSCLC, whether brain metastases were present or not.

\section{Introduction}

Lung cancer is the leading cause of cancer-related mortality worldwide (1). The age-standardized (world) lung cancer mortality rate in Greece shows that one in two cancer-related mortalities in men are caused by lung cancer $(50 \%)$; the figure for women is much lower at $6.3 \%$ (2). The majority of patients (70\%) exhibit advanced disease at the time of diagnosis (3), and 5 years after diagnosis, only $16.6 \%$ of patients remain alive (4).

Research in the field of more effective management of lung cancer is clearly worthwhile, with the goal of increasing survival while maintaining quality of life, and promising advances have been made. The current standard of care for advanced non-small cell lung cancer (NSCLC) is cytotoxic combination chemotherapy with a platinum compound (carboplatin or cisplatin) and one other agent, such as pemetrexed, vinorelbine, paclitaxel, gemcitabine or docetaxel $(5,6)$. Therapy is usually administered for a maximum of 6 cycles unless the disease progresses or there is no response (6).

Pemetrexed inhibits thymidylate synthase and other folate-dependent enzymes involved in the metabolism and synthesis of DNA precursors. A phase III randomized study showed significant survival benefits of pemetrexed over gemcitabine in combination with cisplatin as first-line treatment for non-squamous NSCLC. Median overall survival (OS) was 11.8 months for the pemetrexed arm, with a hazard ratio (HR) of 0.81 [95\% confidence interval (CI), 0.70-0.94; $\mathrm{P}=0.005)$, compared with 10.4 months for gemcitabine (7).

Further survival and disease control benefits have been documented with the addition of bevacizumab to platinum-based chemotherapy doublets in the first-line treatment of non-squamous NSCLC (4). Bevacizumab, a humanized monoclonal antibody against vascular endothelial growth factor, is a vascular-targeted therapy that may inhibit neovascularization. The addition of bevacizumab to chemotherapy combinations resulted in a novel treatment standard based on the results of Eastern Cooperative Oncology Group 
(ECOG) study E4599, first presented at the American Society of Clinical Oncology 2005 meeting and published in full in 2006. Median OS time was 19\% longer when bevacizumab was added to chemotherapy (paclitaxel plus carboplatin) (12.3 vs. 10.3 months respectively; HR for mortality, 0.79; $\mathrm{P}=0.003$ ) (8). Progression-free survival (PFS) was also significantly longer in the bevacizumab group, and survival rates at 1 and 2 years were greater compared with chemotherapy alone (51 and 23\% with bevacizumab, vs. 44 and $15 \%$ without bevacizumab, respectively) (8). The addition of bevacizumab to standard combination chemotherapy appears to improve overall survival (9).

Currently, the combination of bevacizumab plus pemetrexed and a platinum agent has emerged as an important first-line treatment for non-squamous NSCLC. To date, findings with this combination have been reported in only 7 studies: The first phase II study in 2009 (10), 4 further phase II studies (11-14), 1 observational study (15) and 1 population-based study (16). Furthermore, published data for the administration of this combination to patients with brain metastases (BM) have been reported for only few cases, and no comparisons of survival between patients with and without BM are available. More research in this area is clearly required, as the frequency of tumor metastases to the central nervous system is increasing, and it is estimated that $20-40 \%$ of all patients with systemic cancer develop BM (17).

The present single-center observational study aimed to contribute to the current knowledge on the efficacy and safety of combined bevacizumab plus pemetrexed plus carboplatin therapy in patients with advanced non-squamous NSCLC. This analysis includes patients with BM.

\section{Patients and methods}

The present study was an open-label, observational study conducted at the St. Savas Anticancer Hospital in Athens, Greece. Medical records of lung cancer patients treated at the hospital clinic between September 2011 and October 2014 were reviewed for eligibility. All patients were treated once written informed consent was obtained.

Patient eligibility. Patients with inoperable locally advanced stage IIIB or IV non-squamous NSCLC were eligible for the study. The patients should have received bevacizumab plus pemetrexed plus carboplatin as first-line therapy. Further inclusion criteria were an ECOG performance status (PS) score of $\leq 2$ and adequate hematological, hepatic and renal function as follows: Hemoglobin, >9.5 g/dl; absolute neutrophil count, $>1,500 / \mathrm{dl}$; platelet count, $>100,000 / \mathrm{dl}$; international normalized ratio, $<1.5$; total bilirubin, $<1.5$ times the upper normal limit; and serum creatinine, $<2.0 \mathrm{mg} / \mathrm{dl}$. Patients were excluded if they had mixed NSCLC, small cell tumors, mixed adenosquamous carcinoma and if they were epidermal growth factor receptor- or anaplastic lymphoma kinase-positive. Patients with currently non-life threatening BM were included.

Treatment. The treatment schedule consisted of induction therapy with carboplatin (area under the curve, 5), pemetrexed $\left(500 \mathrm{mg} / \mathrm{m}^{2}\right)$ and bevacizumab $(15 \mathrm{mg} / \mathrm{kg})$, every 3 weeks for
Table I. Patient demographics and disease characteristics at the start of treatment $(n=39)$.

\begin{tabular}{|c|c|}
\hline Characteristic & Value \\
\hline \multicolumn{2}{|l|}{ Age in years } \\
\hline Mean (SD) & $60.9(8.9)$ \\
\hline Median (range) & $60.0(44-78)$ \\
\hline Male gender, n (\%) & $25(64.1)$ \\
\hline \multicolumn{2}{|l|}{ Stage, $\mathrm{n}(\%)$} \\
\hline $\mathrm{IIIb}$ & $15(38.5)$ \\
\hline IV & $24(61.5)$ \\
\hline \multicolumn{2}{|l|}{ Histology, n (\%) } \\
\hline Adenocarcinoma & $39(100.0)$ \\
\hline \multicolumn{2}{|l|}{ ECOG PS, n (\%) } \\
\hline 0 & $30(76.9)$ \\
\hline 1 & $8(20.5)$ \\
\hline 2 & $1(2.6)$ \\
\hline \multicolumn{2}{|c|}{ Number of organs with metastasis, $\mathrm{n}(\%)$} \\
\hline One & $26(66.7)$ \\
\hline Two & $8(20.5)$ \\
\hline Three & $4(10.3)$ \\
\hline Four & $1(2.6)$ \\
\hline \multicolumn{2}{|c|}{ Site of metastases, $\mathrm{n}(\%)$} \\
\hline Lungs & $18(46.2)$ \\
\hline Bones & $13(33.3)$ \\
\hline Brain & $11(28.2)$ \\
\hline Liver & $8(20.5)$ \\
\hline Adrenal glands & $3(7.7)$ \\
\hline Pleural effusion & $1(2.6)$ \\
\hline Pleura & $1(2.6)$ \\
\hline Lymph nodes & $1(2.6)$ \\
\hline Pancreas & $1(2.6)$ \\
\hline
\end{tabular}

SD, standard deviation; ECOG, Eastern Cooperative Oncology Group; PS, performance status.

6 cycles. The patients also received vitamin B12 and folic acid supplementation $(1 \mathrm{mg})$ prior to the first chemotherapy administration. Patients without disease progression at the end of induction therapy received bevacizumab $(15 \mathrm{mg} / \mathrm{kg})$ and pemetrexed $\left(500 \mathrm{mg} / \mathrm{m}^{2)}\right.$ as maintenance therapy until disease progression or unacceptable toxicity. An evaluation was performed every 3 cycles.

Response to treatment. Response was assessed using the Response Evaluation Criteria in Solid Tumors, version 1.1 (18). Computed tomography (CT) scans were obtained after the first 2 cycles and every 3 cycles thereafter. The treating physicians assessed the clinical condition of the patients, and documented improvement or worsening, or stable disease (SD). Weight loss, appetite changes, pain levels and pain relief were also documented. The safety profile was monitored and toxicity grades were assigned according to the National Cancer Institute Common Terminology Criteria, version 4 (19). 
Table II. Response to induction therapy following completion of 6 cycles.

\begin{tabular}{|c|c|c|c|c|}
\hline $\begin{array}{l}\text { Clinical response after completion } \\
\text { of } 3 \text { cycles }\left(n=28^{a}\right)\end{array}$ & Total, n (\%) & $\begin{array}{l}\text { Without brain } \\
\text { metastases, } \mathrm{n}\end{array}$ & $\begin{array}{l}\text { With brain } \\
\text { metastases, } \mathrm{n}\end{array}$ & P-value ${ }^{b}$ \\
\hline Stable disease $\mathrm{a}^{\mathrm{a}}$ & $14(50.0)$ & 11 & 3 & 0.482 \\
\hline Partial response & $9(32.1)$ & 8 & 1 & 0.194 \\
\hline Progressive disease & $5(17.9)$ & 3 & 2 & 0.530 \\
\hline Complete response $^{\mathrm{a}}$ & $1(3.6)$ & 0 & 1 & 0.106 \\
\hline
\end{tabular}

${ }^{\mathrm{a}} \mathrm{A}$ complete response was noted in 1 patient with regard to brain disease and stable disease was noted with regard to lung disease. ${ }^{\text {bearson }} \chi^{2}$, for the comparison between 'without brain metastases' and 'with brain metastases'.

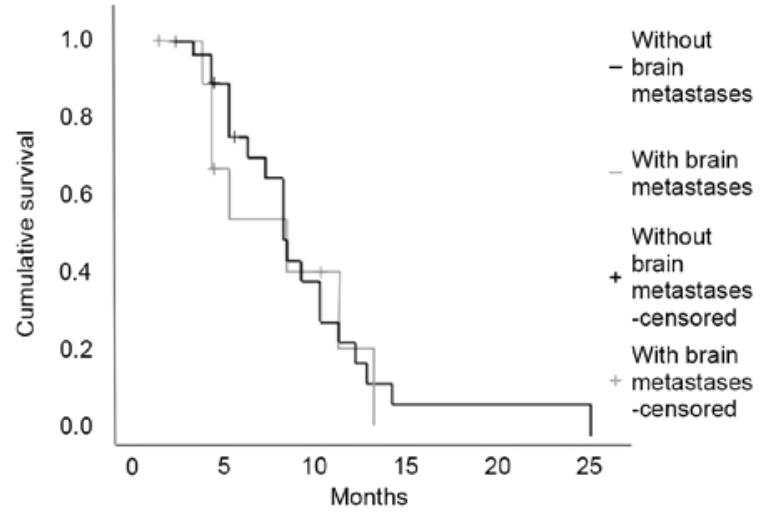

Figure 1. Kaplan-Meier progression-free survival analysis by subgroup of patients with or without brain metastases at diagnosis.

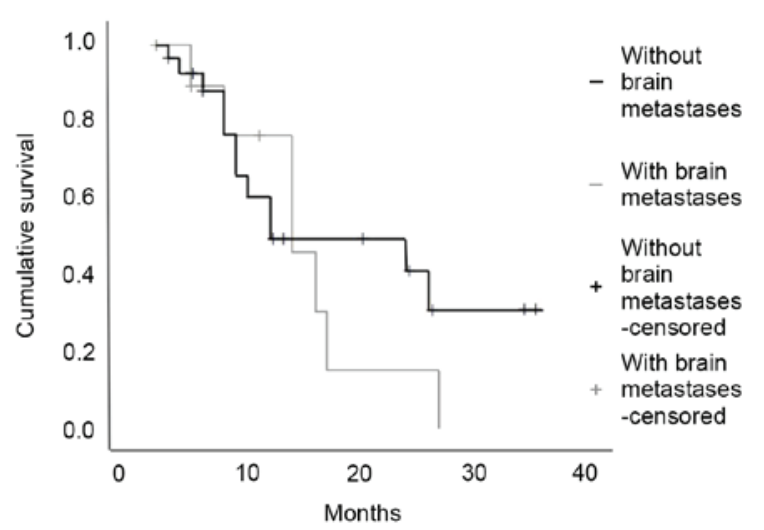

Figure 2. Kaplan-Meier overall survival analysis by subgroup of patients with or without brain metastases at diagnosis.
Data collection and statistical analysis. The primary endpoints were the median PFS and OS times. Survival estimates were calculated using Kaplan-Meier analysis and log-rank (Mantel-Cox) testing for between-group comparisons. PFS time was calculated from the administration of the first cycle to the time of disease progression. OS was calculated from the administration of the first cycle to the time of mortality from any cause. Patients who were alive or remained on treatment at the data cutoff date for the analysis were censored at that date. Actuarial PFS and OS percentages were also calculated via the 'cumulative proportion surviving at end of each month' Life Tables analysis $(20,21)$. Secondary endpoints were safety and response to therapy, namely, a complete response, partial response (PR), SD and progressive disease. Descriptive statistics were used. All analyses were performed with the use of the statistical package SPSS version 13.0 for Windows (SPSS Inc., Chicago, IL, USA).

\section{Results}

Patient characteristics. A total of 39 patients with non-squamous NSCLC were administered induction therapy with bevacizumab plus pemetrexed plus carboplatin as first-line treatment during the study period. Half of the patients were $>60$ years old and the $64.1 \%$ were men (Table I). At diagnosis, 24 patients $(61.5 \%)$ presented with stage IV disease and an ECOG PS score of 0 (Table I). The majority of patients $(66.7 \%)$ exhibited single site metastasis, and most often this was lung or bone metastasis (Table I). In total, 11 patients $(28.2 \%)$ presented with $\mathrm{BM}$, all symptomatic. Upon BM progression, as verified by CT scan, radiotherapy was administered, while study treatment was discontinued and modified accordingly.

Treatment characteristics. Of the 39 patients, $22(56.4 \%)$ completed 6 cycles of induction therapy, 5 patients $(12.8 \%)$ completed 5 cycles, 4 patients $(10.3 \%)$ completed 4 cycles and another 4 patients $(10.3 \%)$ completed 3 cycles. At the end of study follow-up (October 2014), 4 patients remained on treatment. A total of 26 patients received maintenance therapy. Half of these completed $>5$ maintenance therapy cycles (median, 5.5 cycles; range, 1-16 cycles; mean, 6.2 cycles; standard deviation, 3.9 cycles). In total, 13 patients completed $\geq 4$ cycles, 9 patients competed $\geq 6$ cycles, 5 patients completed $1-5$ cycles, 4 patients completed $\geq 10$ cycles and 8 patients remained on treatment upon completion of follow-up.

Response and survival analysis. A total of 28 patients completed 6 cycles of induction therapy, and in half of the patient population, disease was stabilized. From the remaining population, the majority achieved a PR (Table II). Actuarial PFS and OS percentages remained high at 6 months and gradually decreased thereafter (Table III).

Median PFS time was $\sim 8$ months, and OS ranged between 12 and 16 months, with no statistically significant differences between men and women (Table IV). 
Table III. Selected cumulative survival percentages for PFS and OS times at 3, 6, 12, 18 and 24 months calculated via the actuarial life table in monthly interval analysis.

Actuarial survival (\%)

\begin{tabular}{|c|c|c|c|c|c|}
\hline \multirow[b]{2}{*}{$\begin{array}{l}\text { Time } \\
\text { post-treatment }\end{array}$} & \multicolumn{3}{|c|}{ PFS } & \multicolumn{2}{|c|}{ OS } \\
\hline & Total & $\begin{array}{l}\text { With brain } \\
\text { metastases }\end{array}$ & $\begin{array}{l}\text { Without brain } \\
\text { metastases }\end{array}$ & Total & $\begin{array}{l}\text { With brain } \\
\text { metastases }\end{array}$ \\
\hline 3 months & 94 & 89 & 96 & 97 & 100 \\
\hline 6 months & 64 & 52 & 68 & 88 & 88 \\
\hline 12 months & 13 & 20 & 10 & 56 & 76 \\
\hline 18 months & 4 & - & 5 & 38 & 15 \\
\hline 24 months & 4 & - & 5 & 32 & 15 \\
\hline
\end{tabular}

PFS, progression-free survival; OS, overall survival.

Table IV. Median Kaplan-Meier estimates for PFS and OS times (months).

\begin{tabular}{lcc}
\hline & $\begin{array}{c}\text { Median, } \\
\text { months }\end{array}$ & $\begin{array}{c}95 \% \\
\text { confidence } \\
\text { interval }\end{array}$ \\
\hline Parameter & & \\
PFS & 8.2 & $7.05-9.35$ \\
Total & 8.2 & $2.83-13.57$ \\
Patients with brain metastases & 8.0 & $6.77-9.23$ \\
Patients without brain metastases & 8.0 & $4.89-11.11$ \\
Men & 8.2 & $7.70-8.70$ \\
Women & & \\
OS & 14.0 & $8.46-19.54$ \\
Total & 14.0 & $7.52-20.49$ \\
Patients with brain metastases & 12.0 & $0.00-28.46$ \\
Patients without brain metastases & 16.0 & $2.59-29.41$ \\
Men & 12.0 & $6.15-17.85$ \\
Women & &
\end{tabular}

PFS, progression-free survival; OS, overall survival.

Subpopulation of patients with BM at diagnosis. The response to treatment for patients with and without BM did not differ significantly after 3 or 6 months (Table II), nor were there significant differences [log rank (Mantel-Cox)] for median PFS ( $\mathrm{P}=0.748)$ or OS ( $\mathrm{P}=0.447)$ time (Table IV; Figs. 1 and 2$)$. However, the OS survival curve for patients with BM at diagnosis had a much steeper slope, suggesting worse survival for these patients (Fig. 2).

Toxicity. The majority of patients $(30 / 39 ; 76.9 \%)$ did not experience adverse events during treatment. Neutropenia occurred in 4 patients, renal function deterioration in 2 patients, myelotoxicity in 2 patients, hypersensitivity responses to carboplatin in 2 patients, and anemia and fever in 1 patient, respectively. All were manageable and none led to treatment discontinuation or dose modification. There were no treatment-related mortalities.

\section{Discussion}

The present study population consisted of newly diagnosed, treatment-naïve patients with non-squamous metastatic NSCLC with or without BM. Patients received induction therapy with a combination of bevacizumab plus pemetrexed plus carboplatin, followed by maintenance therapy with bevacizumab plus pemetrexed. Analysis showed good survival times and a favorable safety profile in all patients, regardless of the presence of BM.

Findings for the same treatment as in the present study, i.e., induction and maintenance therapy in treatment-naïve non-squamous NSCLC patients, were available from only 7 studies (10-16). The main design characteristics and treatment outcomes of these studies are summarized in Table V. A total of 5 studies were phase II studies (10-14), 1 was a population-based study (16), and only 1 was an observational study with similar design characteristics to the present study (15). The present study results of a median PFS time of 8 months, and a range of OS times of between 12 and 16 months are similar to those reported in these previous trials, in which the shortest PFS time was 5.6 months in the population-based study by Nakamura et al (2012) (16) and the longest was 10.2 months in the phase II study by Spigel et al (2012) (12). For OS, the shortest median was 12.6 months in the PointBreak study by Patel et al (2013) (13) and the longest was 19.3 months in the population-based study by Nakamura et al (2012) (16). Notably, the population-based study of Nakamura et al (2012) (16) reported the shortest median PFS time and the longest median OS time, indicating that a shorter PFS time does not necessary imply a worse OS time. The only study with a design similar to the present study, i.e., an observational, single-center study, was that by Malhotra et al (2010), which did not report median OS and PFS times, but did report response rates (RR) and actuarial survival percentages: $52 \%$ of patients exhibited a PR, disease control was documented for $40 \%$, and the actuarial OS and PFS rates after 12 months were 83 and 63\%, respectively. The corresponding results of the present study were lower than this, but high overall; in terms of RR, the results were close to the $34.1 \%$ reported in the PointBreak study (13) and the $35 \%$ reported in the study by Spigel et al (12). In terms of disease 


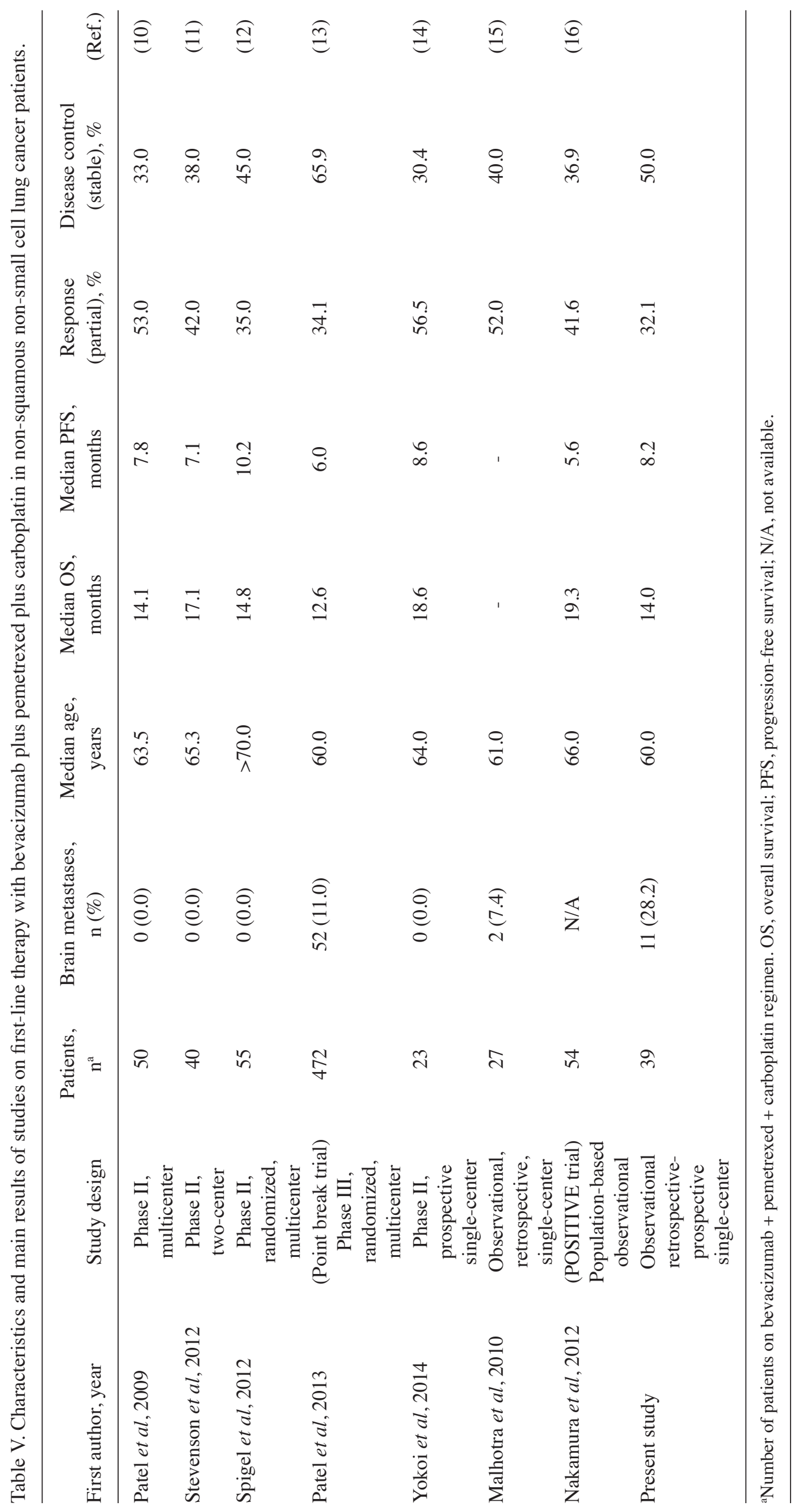


control, the present results lie within the range reported by the remaining studies, with the lowest rate of $30.4 \%$ reported in the study by Yokoi et al (14) and the highest rate of $65.9 \%$ in the PointBreak study (13).

Special attention should be paid to the present findings with regard to the patients with BM. BM are present in $7-10 \%$ of stage IV lung cancer patients at the time of diagnosis, and in $20-40 \%$ following disease progression (22). The incidence of these metastases is increasing (23). Patients with BM have a worse prognosis, a worse quality of life and an increased risk of mortality $(22,24)$, and OS in these patients is extremely poor $(22,25,26)$. Patients with BM used to be treated with steroids and whole-brain radiation therapy. Chemotherapy was not an option due to concerns over the limited permeability of the blood-brain barrier (27). Patients with BM were therefore excluded from chemotherapy and were ineligible for clinical trials (22). Nowadays, it is known that the blood brain barrier is disrupted when brain metastases develop $(27,28)$. Certain trials have been performed on the activity of first-line chemotherapy on brain metastases in NSCLC and have shown response rates ranging from $23-50 \%$ (27). No data, however, have been published for first-line bevacizumab plus pemetrexed plus carboplatin therapy in this group of patients. Indeed, except for the PointBreak study (13), all other studies excluded patients with BM and the population-based study did not report outcomes on such patients (16). In the PointBreak study, the subgroup analysis on the patients with BM did not compare treatment activity between patients with and without BM, however, within the subgroup of patients with BM, it compared the efficacy of the two treatment arms of bevacizumab plus pemetrexed plus carboplatin and bevacizumab plus paclitaxel plus carboplatin. The present study compared patients with and without BM, and did not observe any differences in terms of efficacy and safety between the two groups. The number of patients was small and it is therefore not possible to draw firm conclusions, but it is worth pointing out that despite the worse prognosis of patients with BM, the survival outcomes with bevacizumab plus pemetrexed plus carboplatin were similar to those observed in patients without BM.

To the best of our knowledge, there have been no further reports on the effects of the combination of bevacizumab plus pemetrexed plus carboplatin on non-squamous NSCLC patients with BM, although data with different combinations of the individual components have been published.

For pemetrexed, data regarding patients with BM have been published in the first- and second-line settings. A response rate of $40 \%$ for newly diagnosed BM was reported by Bailon et al (2012) (29) in 30 patients with non-squamous NSCLC following first-line therapy with pemetrexed plus carboplatin. The median OS time was 39 weeks (29). In a phase II study by Barlesi et al (2011) (30), first-line therapy with pemetrexed plus cisplatin resulted in an overall RR of $34.9 \%$ (95\% CI, 21-50.9) and a disease control rate of $72.1 \%$ (overall response plus SD rate). The study enrolled 43 patients with NSCLC and BM. Median OS time was 7.4 months (95\% CI, 5.8-9.6). Positive effects of pemetrexed in second-line treatment (34 patients) and third-line treatment (5 patients) were reported in an observational study by Bearz et al (2010) (31) in 39 patients with advanced NSCLC and BM: $69 \%$ of the patients experienced a clinical benefit (15 PR and 12 SD). Radiological evidence for a cerebral benefit that included PR and stable brain disease was recorded in $82 \%$ of the patients ( 32 patients). The median OS time was 10 months. The results of these three studies indicate that pemetrexed is a good treatment option in such patients (29-31).

With regard to carboplatin in patients with BM, Bernardo et al (2002) (32) reported an RR of $45 \%$ for carboplatin plus vinorelbine plus gemcitabine in the first-line setting. The study enrolled 22 patients with NSCLC and BM, with a median survival time of 33 weeks (range, 18-62 weeks) (32). Edelman et al (2010) (33) evaluated the activity of the doublets carboplatin plus gemcitabine, paclitaxel plus gemcitabine and carboplatin plus paclitaxel in 1,135 patients with advanced NSCLC. A median OS time of 7.7 months (95\% CI, 6.7-9.3) and an RR of $28.9 \%$ were achieved in the 194 patients $(17.1 \%)$ with BM (33).

Regarding the use of bevacizumab in NSCLC patients with BM, it should be mentioned that such patients were initially excluded from the relative studies. This was due to alleged concerns over an increased risk of intracranial hemorrhage after the mortality due to cerebral hemorrhage of a woman with hepatocellular carcinoma treated in a phase I study $(28,34,35)$. Hepatocellular carcinoma, however, may itself lead to cerebral hemorrhage due to impaired liver function and subsequent coagulopathy $(34,36)$. Furthermore, accumulated safety data do not show an increased incidence of cerebral hemorrhage in patients with NSCLC and central nervous system (CNS) metastases. Such patients should therefore not be denied bevacizumab treatment $(34,37,38)$. A retrospective analysis of safety data from 13 randomized controlled trials with 4,760 patients under bevacizumab therapy (91 with CNS metastases) did not show an increased risk of developing cerebral hemorrhage while on treatment with bevacizumab (34). The phase II PASSPORT study was specifically designed to evaluate the safety of the administration of bevacizumab in 115 patients with non-squamous NSCLC and BM (38). Bevacizumab was administered in the first- $(n=76)$ or second-line $(n=39)$ setting in different combinations with chemotherapeutic agents. No grade $\geq 2$ cerebral hemorrhage was observed (38). The ARIES observational study evaluated the efficacy and safety of bevacizumab plus chemotherapy in 1,967 treatment-naïve patients with advanced NSCLC; $8 \%$ of the patients exhibited BM (39). Overall, 1.2\% of the total population suffered from pulmonary hemorrhage and $0.2 \%$ from grade 3-5 CNS hemorrhage. The median OS time was 13.0 months (95\% CI, 12.2-13.8 months). In general, the efficacy and safety profiles were similar to the results reported in the large phase III trials, SAIL (40) and E4599 (8), and the phase IV AVAIL study (41). Although patients with BM are no longer considered ineligible for bevacizumab administration (4) and the European Medicines Agency (EMA) removed label restriction on March 25, 2009, to allow patients with untreated CNS metastases to receive bevacizumab $(42,43)$, information regarding its activity in non-squamous NSCLC patients with BM is lacking.

The present findings in everyday clinical practice with bevacizumab plus pemetrexed plus carboplatin as first-line therapy for non-squamous NSCLC therefore contribute to the better understanding of the activity of this regimen in this population, including patients with BM. 
The observational design of the present study is a limitation, as it is susceptible to systemic bias, for example, data entry errors, reporting errors, missing data and unrecorded confounders. However, such a design reflects the everyday clinical setting and has fewer restrictions than a controlled phase II study. The small sample size is a further limitation that could be overcome in future analyses with a multicenter collaborative design. The major strength of the study is its contribution to the current understanding of the activity of bevacizumab plus pemetrexed plus carboplatin in the first-line therapy of advanced non-squamous NSCLC patients, including those with BM.

Overall, induction treatment with a combination of bevacizumab plus pemetrexed plus carboplatin, followed by bevacizumab plus pemetrexed as maintenance therapy in a small number of patients in the everyday setting was effective and well tolerated in advanced NSCLC, with similar survival benefits for patients with and without BM, despite the worse prognosis of the former.

\section{References}

1. Ferlay J, Soerjomataram I, Dikshit R, Eser S, Mathers C, Rebelo M, Parkin DM, Forman D and Bray F: Cancer incidence and mortality worldwide: Sources, methods and major patterns in GLOBOCAN 2012. Int J Cancer 136: E359-E386, 2015.

2. Atlas of cancer mortality in the European union and the European Economic Area: 1993-1997. IARC Sci Publ: 1-259, 2008.

3. Besse B, Adjei A, Baas P, Meldgaard P, Nicolson M, Paz-Ares L, Reck M, Smit EF, Syrigos K, Stahel R, et al: 2nd ESMO consensus conference on lung cancer: Non-small-cell lung cancer first-line/second and further lines of treatment in advanced disease. Ann Oncol 25: 1475-1484, 2014.

4. NCCN: National Comprehensive Cancer Network (NCCN) Clinical Practice Guidelines in Oncology: Non-Small Cell Lung Cancer. Version I. 2015 (https://www.nccn.org/professionals/ physician_gls/pdf/nscl.pdf).

5. National Cancer Institute: $\mathrm{PDQ}^{\circledR}$ Non-Small Cell Lung Cancer Treatment. Bethesda, MD: National Cancer Institute (http://www. cancer.gov/types/lung/hp/non-small-cell-lung-treatment-pdq). Accessed Nov 26, 2014.

6. Azzoli CG, Baker S Jr, Temin S, Pao W, Aliff T, Brahmer J, Johnson DH, Laskin JL, Masters G, Milton D, et al: American society of clinical oncology clinical practice guideline update on chemotherapy for stage IV non-small-cell lung cancer. J Clin Oncol 27: 6251-6266, 2009.

7. Scagliotti GV, Parikh P, von Pawel J, Biesma B, Vansteenkiste J, Manegold C, Serwatowski P, Gatzemeier U, Digumarti R, Zukin M, et al: Phase III study comparing cisplatin plus gemcitabine with cisplatin plus pemetrexed in chemotherapy-naive patients with advanced-stage non-small-cell lung cancer. J Clin Oncol 26: 3543-3551, 2008.

8. Sandler A, Gray R, Perry MC, Brahmer J, Schiller JH, Dowlati A, Lilenbaum R and Johnson DH: Paclitaxel-carboplatin alone or with bevacizumab for non-small-cell lung cancer. $\mathrm{N}$ Engl $\mathrm{J}$ Med 355: 2542-2550, 2006.

9. Schmid-Bindert G: Update on antiangiogenic treatment of advanced non-small cell lung cancer (NSCLC). Target Oncol 8: 15-26, 2013.

10. Patel JD, Hensing TA, Rademaker A, Hart EM, Blum MG, Milton DT and Bonomi PD: Phase II study of pemetrexed and carboplatin plus bevacizumab with maintenance pemetrexed and bevacizumab as first-line therapy for nonsquamous non-small-cell lung cancer. J Clin Oncol 27: 3284-3289, 2009.

11. Stevenson JP, Langer CJ, Somer RA, Evans TL, Rajagopalan K, Krieger K, Jacobs-Small M, Dyanick N, Milcarek B, Coakley S, et al: Phase 2 trial of maintenance bevacizumab alone after bevacizumab plus pemetrexed and carboplatin in advanced, nonsquamous nonsmall cell lung cancer. Cancer 118: 5580-5587, 2012.

12. Spigel DR, Hainsworth JD, Shipley DL, Ervin TJ, Kohler PC LubinerET,PeytonJD, WaterhouseDM,BurrisHAIIIandGrecoFA: A randomized phase II trial of pemetrexed/gemcitabine/bevacizumab or pemetrexed/carboplatin/bevacizumab in the first-line treatment of elderly patients with advanced non-small cell lung cancer. J Thorac Oncol 7: 196-202, 2012.
13. Patel JD, Socinski MA, Garon EB, Reynolds CH, Spigel DR, Olsen MR, Hermann RC, Jotte RM, Beck T, Richards DA, et al: PointBreak: A randomized phase III study of pemetrexed plus carboplatin and bevacizumab followed by maintenance pemetrexed and bevacizumab versus paclitaxel plus carboplatin and bevacizumab followed by maintenance bevacizumab in patients with stage IIIB or IV nonsquamous non-small-cell lung cancer. J Clin Oncol 31: 4349-4357, 2013.

14. Yokoi T, Torii Y, Katashiba Y, Sugimoto H, Tanijiri T, Ogata M, Inagaki N, Kibata K, Hayashi M, Niki M, et al: Phase II study of pemetrexed and carboplatin plus bevacizumab, followed by maintenance pemetrexed and bevacizumab in Japanese patients with non-squamous non-small cell lung cancer. Oncol Lett 8: 2453-2457, 2014.

15. Malhotra B, Evans T, Weiss J, Eaby B, Stonehouse-Lee S, Sherry V and Langer CJ: Carboplatin/pemetrexed/bevacizumab in the treatment of patients with advanced non-small-cell lung cancer: A single-institution experience. Clin Lung Cancer 11: 192-197, 2010.

16. Nakamura H, Satoh H, Kaburagi T, Nishimura Y, Shinohara Y, Inagaki M, Endo T, Saito T, Hayashihara K, Hizawa N, et al: Bevacizumab-containing chemotherapy for non-small cell lung cancer patients: A population-based observational study by the Ibaraki thoracic integrative (POSITIVE) research group. Med Oncol 29: 3202-3206, 2012.

17. NCCN: National Comprehensive Cancer Network (NCCN) Clinical Practice Guidelines in Oncology: Central Nervous System Cancers. Version 2. 2014 (www.nccn.org/professionals/ physician_gls/PDF/cns.pdf).

18. Eisenhauer EA, Therasse P, Bogaerts J, Schwartz LH, Sargent D, Ford R, Dancey J, Arbuck S, Gwyther S, Mooney M, et al: New response evaluation criteria in solid tumours: Revised RECIST guideline (version 1.1). Eur J Cancer 45: 228-247, 2009.

19. NIH: Common Terminology Criteria for Adverse Events (CTCAE) Version 4.0 (evs.nci.nih.gov/ftp1/CTCAE/ CTCAE_4.03_2010-06-14_QuickReference_5x7.pdf).

20. Compton CC, Byrd DR, Garcia-Aguilar J, Kurtzman SH, Olawaiye A and Washington MK (eds): AJCC Cancer Staging Atlas: A Companion to the Seventh Editions of the AJCC Cancer Staging Manual and Handbook. In: AJCC Cancer Staging Atlas: A Companion to the Seventh Editions of the AJCC Cancer Staging Manual and Handbook. 2nd edition. Springer, New York, 2012.

21. Parkin DM and Hakulinen T: Cancer registration: Principles and methods. Analysis of survival. IARC Sci Publ: 159-176, 1991

22. Ali A, Goffin JR, Arnold A and Ellis PM: Survival of patients with non-small-cell lung cancer after a diagnosis of brain metastases. Curr Oncol 20: e300-e306, 2013.

23. Davis FG, Dolecek TA, McCarthy BJ and Villano JL: Toward determining the lifetime occurrence of metastatic brain tumors estimated from 2007 United States cancer incidence data. Neuro Oncol 14: 1171-1177, 2012.

24. Patchell RA, Tibbs PA, Walsh JW, Dempsey RJ, Maruyama Y, Kryscio RJ, Markesbery WR, Macdonald JS and Young B: A randomized trial of surgery in the treatment of single metastases to the brain. N Engl J Med 322: 494-500, 1990.

25. Louie AV, Rodrigues G, Yaremko B, Yu E, Dar AR, Dingle B, Vincent M, Sanatani M, Younus J, Malthaner R and Inculet R: Management and prognosis in synchronous solitary resected brain metastasis from non-small-cell lung cancer. Clin Lung Cancer 10: 174-179, 2009.

26. Schuette W: Treatment of brain metastases from lung cancer: Chemotherapy. Lung Cancer 45 (Suppl 2): S253-S257, 2004.

27. Zimmermann S, Dziadziuszko R and Peters S: Indications and limitations of chemotherapy and targeted agents in non-small cell lung cancer brain metastases. Cancer Treat Rev 40: 716-722, 2014.

28. D'Antonio C, Passaro A, Gori B, Del Signore E, Migliorino MR, Ricciardi S, Fulvi A and de Marinis F: Bone and brain metastasis in lung cancer: Recent advances in therapeutic strategies. Ther Adv Med Oncol 6: 101-114, 2014.

29. Bailon O, Chouahnia K, Augier A, Bouillet T, Billot S, Coman I, Ursu R, Belin C, Zelek L, Des Guetz G, et al: Upfront association of carboplatin plus pemetrexed in patients with brain metastases of lung adenocarcinoma. Neuro Oncol 14: 491-495, 2012.

30. Barlesi F, Gervais R, Lena H, Hureaux J, Berard H, Paillotin D, Bota S, Monnet I, Chajara A and Robinet G: Pemetrexed and cisplatin as first-line chemotherapy for advanced non-small-cell lung cancer (NSCLC) with asymptomatic inoperable brain metastases: A multicenter phase II trial (GFPC 07-01). Ann Oncol 22: 2466-2470, 2011. 
31. Bearz A, Garassino I, Tiseo M, Caffo O, Soto-Parra H, Boccalon M, Talamini R, Santoro A, Bartolotti M, Murgia V, et al: Activity of pemetrexed on brain metastases from non-small cell lung cancer. Lung Cancer 68: 264-268, 2010.

32. Bernardo G, Cuzzoni Q, Strada MR, Bernardo A, Brunetti G, Jedrychowska I, Pozzi U and Palumbo R: First-line chemotherapy with vinorelbine, gemcitabine, and carboplatin in the treatment of brain metastases from non-small-cell lung cancer: A phase II study. Cancer Invest 20: 293-302, 2002.

33. Edelman MJ, Belani CP, Socinski MA, Ansari RH, Obasaju CK, Chen R, Monberg MJ and Treat J; Alpha Oncology Research Network: Outcomes associated with brain metastases in a three-arm phase III trial of gemcitabine-containing regimens versus paclitaxel plus carboplatin for advanced non-small cell lung cancer. J Thorac Oncol 5: 110-116, 2010.

34. Besse B, Lasserre SF, Compton P, Huang J, Augustus S and Rohr UP: Bevacizumab safety in patients with central nervous system metastases. Clin Cancer Res 16: 269-278, 2010.

35. Gordon MS, Margolin K, Talpaz M, Sledge GW Jr, Holmgren E, Benjamin R, Stalter S, Shak S and Adelman D: Phase I safety and pharmacokinetic study of recombinant human anti-vascular endothelial growth factor in patients with advanced cancer. J Clin Oncol 19: 843-850, 2001.

36. Morgensztern D and Govindan R: Treatment of patients excluded from Eastern Cooperative Oncology Group 4599 and AVAiL studies: Focus on brain metastasis and squamous histology. Clin Lung Cancer 9 (Suppl 2): S57-S61, 2008.

37. Oh Y and Stewart DJ: Systemic therapy for lung cancer brain metastases: A rationale for clinical trials. Oncology (Williston Park) 22: 168-178; discussion 178, 183, 188 passim, 2008.
38. Socinski MA, Langer CJ, Huang JE, Kolb MM, Compton P, Wang L and Akerley W: Safety of bevacizumab in patients with non-small-cell lung cancer and brain metastases. J Clin Oncol 27: 5255-5261, 2009.

39. Lynch TJ Jr, Spigel DR, Brahmer J, Fischbach N, Garst J, Jahanzeb M, Kumar P, Vidaver RM, Wozniak AJ, Fish S, et al: Safety and effectiveness of bevacizumab-containing treatment for non-small-cell lung cancer: Final results of the ARIES observational cohort study. J Thorac Oncol 9: 1332-1339, 2014.

40. Crinò L, Dansin E, Garrido P, Griesinger F, Laskin J, Pavlakis N, Stroiakovski D, Thatcher N, Tsai CM, Wu YL and Zhou C: Safety and efficacy of first-line bevacizumab-based therapy in advanced non-squamous non-small-cell lung cancer (SAiL, MO19390): A phase 4 study. Lancet Oncol 11: 733-740, 2010.

41. Reck M, von Pawel J, Zatloukal P, Ramlau R, Gorbounova V, Hirsh V, Leighl N, Mezger J, Archer V, Moore N and Manegold C: Phase III trial of cisplatin plus gemcitabine with either placebo or bevacizumab as first-line therapy for nonsquamous non-small-cell lung cancer: AVAil. J Clin Oncol 27: 1227-1234, 2009.

42. European Medicines Agency: Committee for Medicinal Products for Human Use Post-Authorisation Summary of Positive Opinion for Avastin. Doc. Ref. No. EMEA/CHMP/121120/2009 (http:// www.ema.europa.eu/docs/en_GB/document_library/Summary_ of_opinion/human/000582/WC500059420.pdf).

43. European Medicines Agency: Assessment Report for Avastin. Doc. Ref. No. EMEA/274499/2009 (http://www.ema.europa.eu/ docs/en_GB/document_library/EPAR_-_Assessment_Report_-Variation/human/000582/WC500029270.pdf). 